\title{
3 Research Square \\ The Different Classification of Hospitals Impact on the Equity of Medical Outcomes of Patients in China
}

Lele Li ( $\square$ lilele1211@163.com)

Renmin University of China

Tiantian Du

Chinese Academy of Social Sciences

siyu zeng

Sichuan University

\section{Research Article}

Keywords: Classification of Chinese hospitals, The equity of Medical Outcomes, NMNL, Disease type

Posted Date: December 17th, 2021

DOI: https://doi.org/10.21203/rs.3.rs-1143832/v1

License: (1) This work is licensed under a Creative Commons Attribution 4.0 International License.

Read Full License 
The Different Classification of Hospitals Impact on the Equity of Medical Outcomes of Patients in China

\begin{tabular}{|c|c|c|}
\hline Lele $\mathbf{L i}^{\mathrm{a} 1}$ & Tiantian $\mathrm{Du}^{\mathrm{b}}$ & Siyu Zeng e1 \\
\hline Le1211@16 & dttvera@126.com & siyuzeng@163.com \\
\hline
\end{tabular}

${ }^{\text {a }}$ School of Labor and Human Resources, Renmin University of China

${ }^{\mathrm{b}}$ Chinese Academy of Labor and Social Security

${ }^{c}$ Business School, Sichuan University

Abstract

${ }^{1}$ Corresponding author 
Background: In the context of Healthy China Strategy, the traditional idea that large hospitals provide better medical care is still deeply rooted in people's minds. The characteristics of the medical inverted pyramid structure - higher-level medical institutions are overwhelmed, while lower-level medical institutions are deserted-have existed for a long time. Because of the unreasonable allocation of resources, it is difficult to meet the healthcare needs of citizens and to establish a tiered delivery system. The objective of this paper is to study the effect of different classification of hospitals $(\mathrm{COH})$ on the equity of Medical Outcomes of patients.

Methods: The data used was from Urban Employee Basic Medical Insurance (UEBMI) enrolment records of Chengdu. We conducted a retrospective study and used Nested Multinomial Logit Model (NMNL) to estimate the effect of $\mathrm{COH}$ on the equity of Medical Outcomes.

Results: $\mathrm{COH}$ had a significant effect on the equity of Medical Outcomes, but the effectiveness and direction of the hospital level on different outcomes were not consistent. The reimbursement rate, medical expenditures, gender, age, disease type and others factors were associated with the $\operatorname{effect}(\mathrm{p}<0.01)$; length of stay has a limited effect on health outcomes. It was not the case that the longer the hospital stay was, the higher the quality of care would be. When $\mathrm{COH}$ was distinguished, there were significant differences in the effect of different levels of hospitals on the equity of Medical Outcomes. Horizontally speaking, hospitals of the same level had different effects on different the equity of Medical Outcomes $(\mathrm{p}<0.01)$. From a longitudinal perspective, different levels of hospitals had different effects on the equity of Medical Outcomes $(\mathrm{p}<0.01)$. It was not the case that the higher the level of hospital, the better the medical outcome. When hospital levels and disease types were distinguished, the effect of hospitals of different levels on the medical outcome of different disease types was significantly different. 
Conclusions: $\mathrm{COH}$ made a difference in the equity of Medical Outcomes. Hospitals of different levels should be reasonably selected according to disease types to achieve the optimal medical outcome. Therefore, China should promote the construction of a tiered delivery system.

Keywords: Classification of Chinese hospitals; The equity of Medical Outcomes; NMNL; Disease type

\section{Background}

The 19th National Congress of the Communist Party of China announced the implementation of a national strategy known as Healthy China Strategy, which has placed population health improvement as the primary strategic goal of the health system. However, for a long time, medical resources in China have been in short supply. Furthermore, the characteristics of the medical inverted pyramid structure - higher-level medical institutions are overwhelmed, while grassroots medical institutions are deserted—has existed for a long time [1]. As shown in Table 1, It is obvious that the mismatch of medical resources and the imbalance of supply and demand create the problem of inaccessible medical care. Lining up for three hours to see a doctor for three minutes and overburdened doctors are characteristics of tertiary hospitals [2]. According to Figure 1, Medical outcome refers to the impact of medical services or medical treatment on a patient's life. The classical Donabedian framework for evaluating remedial services was divided into structural, process, and outcome indicators [9]. Another classical approach was the five aspects, which includes death, disease, disability, discomfort, and dissatisfaction [10]. However, the two classical models had been used less frequently in contemporary outcome research. There were three types of measures for the equity of Medical Outcomes in recent research: the economic outcome model [11], 
the clinical outcome model [12]- [13] and the humanistic outcome model [14]-[15]. Many factors influenced therapeutic outcomes, such as hospital size, hospital type, hospital service capacity, hospital accreditation, hospital competition and medical insurance. Therefore, scholars had used China and other countries as study cases.

Table 1 Hospital outpatient visits: China,2014-2018

\begin{tabular}{|c|c|c|c|c|c|}
\hline \multirow{2}{*}{ Hospital Types } & \multicolumn{5}{|c|}{ Outpatient visits (x108) } \\
\cline { 2 - 6 } & 2014 & 2015 & 2016 & 2017 & 2018 \\
\hline Public hospital & 26.5 & 27.1 & 28.5 & 29.5 & 30.5 \\
\hline Private hospital & 3.3 & 3.7 & 4.2 & 4.9 & 5.3 \\
\hline Tertiary hospital & 14.0 & 15.0 & 16.3 & 17.3 & 18.5 \\
\hline Secondary hospital & 11.5 & 11.7 & 12.2 & 12.7 & 12.8 \\
\hline Primary hospital & 1.9 & 2.1 & 2.2 & 2.2 & 2.2 \\
\hline $\begin{array}{c}\text { Primary health care } \\
\text { institutions }\end{array}$ & 43.6 & 43.4 & 43.7 & 44.3 & 44.1 \\
\hline
\end{tabular}

Data Source: China Health Statistics Yearbook:2014-2018.

The mismatch of medical resources and the imbalance between supply and demand lead to various problems in the operation of China's medical and health system. Li [3] believed that the limited medical resources of tertiary hospitals were seriously occupied by common diseases and chronic diseases, and more than $60 \%$ of patients in tertiary hospitals could be treated in grassroots medical institutions. The effect of hospital classification on medical outcome differed significantly in terms of income. Different income groups were influenced by different levels of hospitals. Li et al. [4] studied the data from the New Rural Cooperative Healthcare system and found that highincome groups increased their utilization of medical services more significantly. At the same time, income difference had a significant impact on health status. Liu and $\mathrm{Hu}$ [5] concluded that the level of health inequality in China was more beneficial to high-income people. 
The effect of hospital classification on medical outcome was also reflected in price and distance. Firstly, the price level of hospitals of different levels was different. The higher the level of hospital, the higher the price of healthcare services. Qian et al. [6] studied the medicinal demand behaviour of rural residents and found that the price elasticity of low-income groups was higher than that of high-income groups. Secondly, in the same area, the higher the hospital level, the farther the distance; the lower the hospital level, the closer the distance. Han [7] suggested that when patients paid attention to medical service quality or suffer from serious diseases, they would consider higher-level hospitals for treatment. Finally, research on the relationship between hospital volume and medical outcome has just begun in China. Taking colorectal cancer surgery as an example, Ma [8] systematically reviewed the clinical data of more than 1 million cases of colorectal cancer patients reported by ten centres from 1999 to 2011 and discussed the effect of the hospital's or surgeon's volume on the complications and prognosis of colorectal cancer patients. The results showed that the volume of operation played a role in the restorative outcome, and a high volume of operation of hospitals and surgeons could reduce the rate of complications and tumour recurrence and improve the prognosis of patients.

The Chinese government has promoted the construction of a tiered delivery system. By establishing a tiered delivery system, the diagnosis and treatment systems can be divided into slight illness in the community, serious diseases in the hospital and rehabilitation back to the community to meet the health needs of people with different types of diseases. However, the idea of better the equity of Medical Outcomes in large hospitals is rooted in people's minds, which is not conducive to the promotion of a tiered delivery system. Is the medical outcome of higher-level hospitals truly better? What effect does $\mathrm{COH}$ have on the equity of Medical Outcomes? The objective of this paper 
is to study the effect of $\mathrm{COH}$ on the equity of Medical Outcomes of patients. This paper conducts an in-depth study of these issues and provides an important decision-making basis for promoting the construction of a tiered delivery system with the hope of providing insights into appropriate care levels by appropriate resource allocation.

\section{Methods}

This paper conducted a retrospective study. Using data derived from the Urban Employee Basic Medical Insurance (UEBMI) of Chengdu City from 2011 to 2015, we explore how does different classification of hospitals impact on the equity of Medical Outcomes of patients.

\section{Theoretical analysis and research hypothesis}

According to the mechanism of the effect of hospital classification on the equity of Medical Outcomes in Figure 2, many factors affect therapeutic outcome, including the characteristics of medical institutions, personal characteristics and potential influencing factors. The impact of personal characteristics on the healing effect are relatively complex and difficult to quantify. Therefore, the theoretical analysis of this paper only involves the characteristics and potential influencing factors of curative institutions.

We assume that the remedial service process involves only hospitals (physicians), patients, and healthcare providers. To distinguish the level of hospitals, the hospitals were divided into superior hospitals and inferior hospitals. In China, medical institutions were designated into primary, secondary or tertiary institutions according to their ability to provide medical care, medical education and medical research. Furthermore, these three grades were subdivided into 3 subsidiary levels, A, B and C, built on the level of hospital scale, service provision, medical technology and 
equipment, medical research and so on. In addition, one special level was appointed to the most advanced hospitals. Therefore, hospitals were divided into 10 levels. This was called the 3-tier system in China. Superior hospitals are the Grade II hospitals and inferior hospitals are Grade I hospitals in this paper. Therefore, the core components of the medical service system include patients, medical insurance institutions, superior hospitals and inferior hospitals. Among them, doctors' decisions are included in the hospital and are not regarded as separate. If only the same type of disease (critical diseases, chronic diseases or common diseases) is considered, both superior hospitals and inferior hospitals have the ability to treat the disease. Patients have subjective cognition of the therapeutic effect of hospitals of different levels. The subjective cognition of patients is based on the reputation and public praise of upper- and lower-level hospitals rather than the actual comparison of treatment effects. Patients believe that the therapeutic effect of upper- and lower-level hospitals differs and that the therapeutic effect of higher-level hospitals is better than that of lower-level hospitals.

In terms of patients, it is assumed that the probability of disease of each resident is $r$, the number of patients is $\mathrm{N}$, and patients have a linear preference. Let the utility function of patients be:

$$
\mathrm{U}=\mathrm{U}(\mathrm{x})+\mathrm{M}=\ln (\mathrm{x})+\mathrm{M},
$$

where $x$ is the personal income of the patient and $M$ is the health status. Suppose $x_{s}=w_{s}-$ $k_{t} p_{t}, t=a, b, w_{s}$ is the initial income of patient $s$ and $w_{s} \in[0, W]$, which obeys a uniform distribution. Health condition $M \in\left[M^{\prime}, M^{\prime \prime}\right]$, where the state after illness is $M^{\prime}$ and the state without disease is $M^{\prime \prime}$.

In terms of hospitals, it is assumed that both superior and inferior hospitals have the ability to 
treat the same disease, and patients choose between superior hospitals $A$ and inferior hospitals $B$. The price of the superior hospital and the inferior hospital is $p_{a}$ and $p_{b}$, the treatment cost is $C_{a}$ and $C_{b}$, and the marginal cost of medical service provided by the hospital remains unchanged. Before choosing a hospital, patients' subjective cognition of the medical quality of the superior hospital and the inferior hospital is $q_{a}$ and $q_{b}$, and patients' subjective cognition after hospital treatment is $M=M\left(q_{t}\right), t=a, b$, and $M^{\prime}<M\left(q_{b}\right)<M\left(q_{a}\right)<M^{\prime \prime}$.

In terms of medical insurance institutions, it is assumed that patients in superior hospitals and inferior hospitals are $n_{a}$ and $n_{b}$, and the reimbursement proportion provided by medical insurance institutions for patients in superior hospitals and inferior hospitals is $k_{a}$ and $k_{b}$.

The total fund expenditure of medical institutions is: $C_{f}=n_{a} \cdot k_{a} \cdot p_{a}+n_{b} \cdot k_{b} \cdot p_{b}$. Therefore, the rest of the fund is: $\pi_{f}=\frac{N}{r} \lambda-n_{a} \cdot k_{a} \cdot p_{a}-n_{b} \cdot k_{b} \cdot p_{b}$,

where $\lambda$ is the premium per patient. For the sake of simplicity, it is deemed to be fully covered by the government, not by the patient. The income of hospitals mainly comes from medical insurance fund payments and patient payments. The medical service price paid by medical insurance funds is guided by the government, while superior hospitals have pricing power for some of their medical services. To simplify the calculation, it is assumed that the reimbursement proportion of lower-level hospitals is $100 \%$ (free restorative treatment), and lower-level hospitals enjoy financial subsidies, and the price is equal to the cost. That is, $p_{k}=p, p_{b}=c_{b}, k_{b}=1$.

According to the price of hospitals of different grades, the reimbursement ratio of medical insurance and subjective cognition of the treatment effect of hospitals of different grades, patients will choose hospitals of different grades to seek treatment to take full advantage of their utility. Patients, medical institutions, superior hospitals and inferior hospitals all have different objective 
functions, which are a process of multiparty dynamic games. The following is the derivation and solution of the model.

There are only three choices for patients to seek medical treatment: superior hospital, inferior hospital and no doctor. The utility is $U^{a}, U^{b}, U^{0}$. Substitute into formula $\left(^{*}\right)$ and obtain:

Choose the superior hospital; its utility is: $U^{a}=\ln \left[w_{s}-\left(1-k_{a}\right) \cdot p\right]+M\left(q_{a}\right)$

Choose the lower hospital; its utility is: $U^{b}=\ln \left[w_{s}-\left(1-k_{b}\right) \cdot p\right]+M\left(q_{b}\right)$

Choose not to go to see a doctor; its utility is: $U^{0}=\ln \left(w_{S}\right)+M^{\prime}$

(1) The first circumstance: choose a superior hospital to see a doctor

If the patient chooses to go to a superior hospital and does not go to a substandard hospital, the following need to be satisfied at the same time:

$$
U^{a}=\ln \left[w_{s}-\left(1-k_{a}\right) \cdot p\right]+M\left(q_{a}\right)>U^{b}=\ln \left(w_{s}\right)+M\left(q_{b}\right)
$$

and

$$
U^{a}=\ln \left[w_{s}-\left(1-k_{a}\right) \cdot p\right]+M\left(q_{a}\right)>U^{0}=\ln \left(w_{s}\right)+M^{\prime} .
$$

Therefore, when $w_{s}>\alpha \cdot\left(1-k_{a}\right) \cdot p$, patients would choose to go to the superior hospital.

At this time, the number of patients is:

$$
n_{a}=N \cdot P\left[w_{s}>\alpha \cdot\left(1-k_{a}\right) \cdot p\right]=N \cdot\left[1-\frac{\alpha \cdot\left(1-k_{a}\right) \cdot p}{W}\right]=N-n_{b} .
$$

(2) The second circumstance: the choice to go to an inferior hospital to see a doctor

If patients choose to see a doctor in an inferior hospital and do not go to a superior hospital, they need to satisfy:

$$
U^{b}=\ln \left(w_{s}\right)+M\left(q_{b}\right) \geq U^{a}=\ln \left[w_{s}-\left(1-k_{a}\right) \cdot p\right]+M\left(q_{a}\right)
$$

and

$$
\ln \left(w_{s}\right)-\ln \left[w_{s}-\left(1-k_{a}\right) \cdot p\right] \geq M\left(q_{a}\right)-M\left(q_{b}\right) .
$$


When $M\left(q_{a}\right)-M\left(q_{b}\right)=h>0$, the following equation can be obtained:

$$
w_{s} \leq \frac{e^{h}}{e^{h}-1} \cdot\left(1-k_{a}\right) \cdot p=\alpha \cdot\left(1-k_{a}\right) \cdot p .
$$

When $\alpha=\frac{e^{h}}{e^{h}-1}, w_{s} \leq \alpha \cdot\left(1-k_{a}\right) \cdot p$, patients choose to go to a lower-level hospital instead of a higher-level hospital.

At this time, the number of patients in hospitals at lower levels is:

$$
n_{a}=N \cdot p\left[w_{s} \leq \alpha \cdot\left(1-k_{b}\right) \cdot p\right]=N \cdot \frac{\alpha \cdot\left(1-k_{b}\right) \cdot p}{W} .
$$

(3) The third situation: choose not to go to the hospital

Because $M\left(q_{b}\right)>M^{\prime}$, so have $U^{b}=\ln \left(w_{s}\right)+M\left(q_{b}\right)>U^{0}=\ln \left(w_{s}\right)+M^{\prime}$,

the patient, as a rational person, will choose to see a doctor in a lower-level hospital between not seeing a doctor in a hospital and seeing a doctor in a lower-level hospital.

In summary, patients have subjective cognition of the medicinal effect of different grades of hospitals based on the factors that affect the medical outcome. On the premise of maximizing its own utility, hospitals of different grades were selected. According to the theoretical analysis of patients' medical treatment choices made in hospitals of different grades on the impact of medical effects, the following research hypotheses can be made:

Hypothesis 1: Hospitals of different grades have different effects on the equity of Medical Outcomes.

Hypothesis 2: Hospitals of different grades have different therapeutic outcomes for different types of diseases.

Hypothesis 3: The medical insurance reimbursement ratio has a significant impact on medical reimbursement. 


\section{Data source and variable description}

The data used in this paper was derived from the Urban Employee Basic Medical Insurance (UEBMI) of Chengdu City from 2011 to 2015. It is not an open-access database. The sample size was $1,035,556$ hospitalized patients. Due to the large number of missing values in the transition state, the sample size was 512,658 hospitalized patients after removing the missing values.

In this study, we defined the independent, dependent and control variables, as shown in table 2. The independent variable was medical outcome, which was mainly measured by treatment outcome and divided into four main types: death, transfer, rehabilitation and no cure. According to previous literature, clinical outcomes were measured as changes in a patient's health and could be used to generate evidence about the clinical benefits of medical services [14]. Death referred to patients who were not cured in medical institutions and lose their lives. Transfer referred to patients treated from one hospital to another hospital. Rehabilitation meant that patients were cured in medical institutions and recover function. Others indicated no cure, which referred to the other conditions besides death, transfer and rehabilitation. Death, transfer and no cure were negative outcomes, while rehabilitation was a positive outcome. Therefore, rehabilitation was invoked as the reference group for the model. Dependent variables were the factors that affect patients' therapeutic outcome. Dependent variables mainly included medical institution characteristic factors, patient characteristic factors and potential influencing factors. The principal factor of medical institution characteristics was the hospital's own level, which was designated according to the classification standard of hospitals in China, which designated medical institutions as primary, secondary or tertiary institutions according to their ability to provide medical care, medical education and medical research. According to the classification standard of hospitals in China, large hospitals in this paper 
were mainly Grade II Level A hospitals. Potential influencing factors were the price factor, which was measured primarily by medical expense and reimbursement ratio. The reimbursement ratio was an exogenous variable that patients could not know the actually. However, patients' behaviour was influenced by the reimbursement ratio. They choosed the level of hospital to maximize their own interests, which had significant effects on the patient's medical outcome. The effect of medical expenses on patients' choice of homeopathic treatment was obvious. Patients choosed fewer medical expenses from hospitals, which also affected the medical outcome. Therefore, the reimbursement ratio and medical expenses were both potential factors that affect the therapeutic outcome of patients. Individual characteristic factors included age, gender and length of stay. According to the international diagnostic code ICD-10, disease types were mainly divided into chronic diseases, critical diseases and common diseases. Chronic diseases were considered the reference group.

Table 2 Variable definition and Descriptive statistics

\begin{tabular}{|c|c|c|c|c|c|}
\hline \multicolumn{2}{|c|}{ Variable type } & Variable name & Variable definition & Mean & SD \\
\hline \multicolumn{6}{|c|}{ Explained variable } \\
\hline \multirow{4}{*}{$\begin{array}{l}\text { medical } \\
\text { effect }\end{array}$} & \multirow{4}{*}{$\begin{array}{l}\text { treatment } \\
\text { outcome }\end{array}$} & death & death $=1$, otherwise $=0$ & 0.01 & 0.11 \\
\hline & & Transfer & $\begin{aligned} \text { Transfer } & =1, \text { otherwise } \\
& =0\end{aligned}$ & 0.03 & 0.12 \\
\hline & & Rehabilitation & $\begin{array}{c}\text { Rehabilitation }=1, \\
\text { otherwise }=0\end{array}$ & 0.91 & 0.29 \\
\hline & & Others & others $=1$, otherwise $=0$ & 0.05 & 0.21 \\
\hline \multicolumn{6}{|c|}{ Explanatory variables } \\
\hline \multirow{3}{*}{ hospitals } & \multirow{3}{*}{$\begin{array}{c}\text { classification of } \\
\text { hospitals }\end{array}$} & $\begin{array}{c}\text { Grade II Level } \\
\text { A }\end{array}$ & $\begin{array}{c}\text { Grade II Level A }=1, \\
\text { otherwise }=0\end{array}$ & 0.83 & 0.37 \\
\hline & & $\begin{array}{c}\text { Grade II Level } \\
\text { B } \\
\end{array}$ & $\begin{array}{c}\text { Grade II Level B }=1, \\
\text { otherwise }=0\end{array}$ & 0.12 & 0.33 \\
\hline & & Grade I & Grade $\mathrm{I}=1$,otherwise $=0$ & 0.03 & 0.16 \\
\hline \multicolumn{6}{|c|}{ Control variables } \\
\hline $\begin{array}{c}\text { Potential } \\
\text { influencing }\end{array}$ & & $\begin{array}{c}\text { Grade II Level } \\
\text { A }\end{array}$ & $\begin{array}{l}\text { Average reimbursement } \\
\text { ratio in Grade II Level A }\end{array}$ & 0.71 & 0.16 \\
\hline
\end{tabular}




\begin{tabular}{|c|c|c|c|c|c|}
\hline \multirow[t]{6}{*}{ factors } & \multirow{3}{*}{$\begin{array}{c}\text { Reimbursement } \\
\text { ratio }\end{array}$} & & hospitals & & \\
\hline & & $\begin{array}{c}\text { Grade II Level } \\
\text { B }\end{array}$ & $\begin{array}{c}\text { Average reimbursement } \\
\text { ratio in Grade II Level B } \\
\text { hospitals }\end{array}$ & 0.64 & 0.15 \\
\hline & & Grade I & $\begin{array}{l}\text { Average reimbursement } \\
\text { ratio in Grade I hospitals }\end{array}$ & 0.69 & 0.17 \\
\hline & \multirow{3}{*}{$\begin{array}{l}\text { Medical } \\
\text { expenses }\end{array}$} & $\begin{array}{c}\text { Grade II Level } \\
\text { A }\end{array}$ & $\begin{array}{c}\text { Average medical } \\
\text { expenses in Grade II } \\
\text { Level A hospitals }\end{array}$ & 6024.85 & 6527.37 \\
\hline & & $\begin{array}{c}\text { Grade II Level } \\
\text { B }\end{array}$ & $\begin{array}{l}\text { Average medical } \\
\text { expenses in Grade II } \\
\text { Level B hospitals } \\
\end{array}$ & 3917.81 & 4000.12 \\
\hline & & Grade I & $\begin{array}{c}\text { Average medical } \\
\text { expenses in Grade I } \\
\text { hospitals }\end{array}$ & 4453.76 & 3849.22 \\
\hline \multirow{3}{*}{\multicolumn{2}{|c|}{$\begin{array}{l}\text { Individual characteristic } \\
\text { factors }\end{array}$}} & Gender & female $=1$, others $=0$ & 0.52 & 0.50 \\
\hline & & Age & Age of participant & 86.28 & 23.81 \\
\hline & & length of stay & Actual length of stay & 9.61 & 43.42 \\
\hline \multirow{3}{*}{\multicolumn{2}{|c|}{ Disease types }} & $\begin{array}{l}\text { Chronic } \\
\text { disease }\end{array}$ & $\begin{array}{c}\text { chronic disease }=1, \\
\text { otherwise }=0\end{array}$ & 0.05 & 0.21 \\
\hline & & $\begin{array}{l}\text { Critical } \\
\text { disease }\end{array}$ & $\begin{array}{c}\text { critical disease }=1, \\
\text { otherwise }=0\end{array}$ & 0.06 & 0.23 \\
\hline & & Others & others $=1$, otherwise $=0$ & 0.89 & 0.30 \\
\hline
\end{tabular}

As seen in table 2, rehabilitation accounted for the highest proportion of the treatment outcome and that Grade II Level A hospitals accounted for the highest proportion of hospitals. The patients were mainly elderly, with an average age of 86.28 years old. The average length of stay was 9.61 days. There was no notable gender difference. In terms of the reimbursement ratio, the actual reimbursement ratio of Grade II Level A hospitals is higher than that of Grade II Level B hospitals and below. Surprisingly, the reimbursement ratio of Grade II Level B is the lowest among all hospitals. In terms of medical expenses, the average medical expenses of Grade II Level A hospitals are the highest. The medical institutions with the lowest average medical expenses are Grade II Level B hospitals. The average medical expenses of Grade II Level C hospitals are in the middle, 
which may be related to more prescriptions from grassroots institutions.

\section{Model setting}

Referring to the existing literature, this paper established the model as follows:

$$
\operatorname{prob}\left(\text { result }_{\mathrm{i}}\right)=\beta_{0}+\beta_{1} \operatorname{rank}_{\mathrm{i}}+\beta_{2} \mathrm{X}_{\mathrm{i}}+\varepsilon_{\mathrm{i}}
$$

where $\mathrm{i}$ represents the $\mathrm{i}$ patient in the sample, result $\mathrm{i}_{\mathrm{i}}$ represents the medical outcome of the i patient, rank $_{\mathrm{i}}$ represented the effect degree of classification of hospital on the i patient, $\mathrm{X}_{\mathrm{i}}$ represented a group of observable control variables, and $\varepsilon_{\mathrm{i}}$ represents the error term.

The multinomial logit model (MNL) was a classic model for health care demand behaviour [1], health care choice [2] and other issues. A model was a discrete model with a finite number of options that had to satisfy the independence of irrelevant alternatives (IIA): the relativistic logarithmic ratio required to be mutually exclusive was dependent on characteristics belonging to both results and was irrelevant to the quantity and properties of all other results considered. In other words, the multinomial logit model (MNL) had to satisfy the fact that there was no strong similarity between multiple options at the discrete level. Otherwise, it would produce the error of coefficient estimation. In most cases, this hypothesis was difficult to satisfy. To compensate for the deficiency of the MNL model, Han [7] proposed the nested multinomial logit model (NMNL). This model nests all options by dividing them into several unrelated subsets, which could make each option satisfy the objective unrelated hypothesis (IIA). The explanatory variables of the NMNL model mainly had two characteristics, which were different from the general multinomial logit model. First, dependent variables changed with individual changes, such as gender, age, and consumption. Second, dependent variables changed with the overall changes, such as programmes, policies, and projects. 
Many factors affected the the equity of Medical Outcomes of patients. On the one hand, the curative outcome of patients was affected by individual characteristics such as gender and age. On the other hand, it was affected by medical institution characteristics, such as price, medical equipment, medical level and social reputation, which reflected the heterogeneity of medical institutions. The general multinomial logit model could only deal with the first type of variables that change with characteristic changes. It could not deal with the second type of variables that changed with the overall changes. However, NMNL model could meet the need to deal with two types of variables at the same time, which was more suitable to analyse the influencing factors of the equity of Medical Outcomes.

\section{Results}

\section{Empirical results analysis}

To estimate the effect of the $\mathrm{COH}$ on the equity of Medical Outcomes, this paper used UEBMI data of Chengdu City to conduct MMHL model analysis. The empirical results were presented in table 3.

According to the empirical results, the hospital level had a significant impact on the therapeutic outcome, but the degree of influence and direction of different outcome states were not consistent. The effect of hospital level on death and transfer was significantly positive, but the effect on no cure was significantly negative, which could be related to the type and severity of diseases. The effect of the medical insurance reimbursement ratio on death and transfer was significantly positive, while the impact on no cure was significantly negative. This indicates that a higher reimbursement ratio of medical insurance was not appropriate. The government should establish a different 
reimbursement ratio for different disease types. According to Figure 3, reimbursement rates were mainly between $60 \%$ and $95 \%$, and there were sizable differences in reimbursement rates among different hospital grades. However, more detailed reimbursement rates were not set for different disease types. The effect of medical expenses on treatment outcome was significantly positive, which indicated that medical expenditures had a significant impact on the equity of Medical Outcomes. The more medical expenditures there were, the better the therapeutic outcome was likely to be. Distinct characteristics also had a significant effect on therapeutic outcomes. Gender had a significant negative effect on death and transfer and a significant positive effect on no cure, indicating that gender had an important impact on the equity of Medical Outcomes. In terms of death and transfer, females had better the equity of Medical Outcomes than males. The effect of age on death and transfer was markedly positive, while the effect on no cure was negative, indicating that the older the age, the higher the probability of death and transfer. The length of days in the hospital had a negative impact on the medical outcome, indicating that more days in the hospital were not necessarily correlated with better the equity of Medical Outcomes. The effect of disease type on death and no cure was significantly negative, indicating that the more severe the disease type was, the higher the probability of death and no cure. The effect of disease type on transfer was positive, indicating that when the disease type was serious, hospital transfer could occur spontaneously or involuntarily.

Table 3 NMNL Empirical Results

\begin{tabular}{|c|c|c|c|c|}
\hline \multirow{2}{*}{ Variables } & \multicolumn{4}{|c|}{ Treatment outcome } \\
\cline { 2 - 5 } & Medical effect & Death & Transfer & Others \\
\hline \multirow{2}{*}{ Hospital levels } & $0.3271^{* * *}$ & $0.4817^{* * *}$ & $1.8231^{* * *}$ & $-0.3392^{* * * *}$ \\
& $(10.35)$ & $(14.65)$ & $(101.15)$ & $(-13.14)$ \\
\hline reimbursement & & $-1.0619^{* * *}$ & $-1.2951^{* * *}$ & $6.4000^{* * *}$ \\
ratio & & $(-11.58)$ & $(-18.50)$ & $(87.48)$ \\
\hline
\end{tabular}




\begin{tabular}{|c|c|c|c|c|}
\hline $\begin{array}{c}\text { medical } \\
\text { expenses }\end{array}$ & & $\begin{array}{c}0.6125^{* * *} \\
(30.36) \\
\end{array}$ & $\begin{array}{c}0.0745^{* * *} \\
(4.49)\end{array}$ & $\begin{array}{c}0.1513 * * * \\
(10.25)\end{array}$ \\
\hline gender & & $\begin{array}{c}-0.4608 * * * \\
(-18.16)\end{array}$ & $\begin{array}{c}-0.0760 * * * \\
(-4.42)\end{array}$ & $\begin{array}{c}0.0691 * * * \\
(5.16)\end{array}$ \\
\hline age & & $\begin{array}{c}0.0388^{* * *} \\
(46.06) \\
\end{array}$ & $\begin{array}{c}0.0088^{* * *} \\
(21.76) \\
\end{array}$ & $\begin{array}{c}-0.0018^{* * *} \\
(-4.52) \\
\end{array}$ \\
\hline Length of day & & $\begin{array}{l}-0.0002 \\
(-0.20) \\
\end{array}$ & $\begin{array}{c}-0.1284 * * * \\
(-41.14)\end{array}$ & $\begin{array}{c}-0.0036^{* * *} \\
(-3.68) \\
\end{array}$ \\
\hline Disease type & & $\begin{array}{c}-0.1268 * * * \\
(-5.46) \\
\end{array}$ & $\begin{array}{l}0.0125 \\
(0.60) \\
\end{array}$ & $\begin{array}{c}-0.2248 * * * \\
(-20.43) \\
\end{array}$ \\
\hline Constant term & $\begin{array}{c}-4.6342 * * * \\
(-117.17)\end{array}$ & $\begin{array}{c}-12.5374 * * * \\
(-64.27)\end{array}$ & $\begin{array}{c}-5.3939 * * * \\
(-42.47)\end{array}$ & $\begin{array}{c}-8.2196^{* * *} \\
(-66.98)\end{array}$ \\
\hline Log likelihood & -193657.9 & \multicolumn{3}{|c|}{-179366.71} \\
\hline Prob $>$ chi 2 & 0.0000 & \multicolumn{3}{|c|}{0.0000} \\
\hline Pseudo R2 & 0.0343 & \multicolumn{3}{|c|}{0.1056} \\
\hline $\mathrm{N}$ & 512658 & \multicolumn{3}{|c|}{512658} \\
\hline
\end{tabular}

Table 4 NMNL Empirical Results (by hospital levels)

\begin{tabular}{|c|c|c|c|c|c|c|c|c|c|}
\hline \multirow{2}{*}{ Variables } & \multicolumn{9}{|c|}{ Treatment outcome } \\
\hline & Death & Transfer & Others & Death & Transfer & Others & Death & Transfer & Others \\
\hline \multicolumn{10}{|l|}{$\begin{array}{l}\text { Hospital } \\
\text { levels }\end{array}$} \\
\hline $\begin{array}{l}\text { Grade II } \\
\text { Level A } \\
\text { hospitals }\end{array}$ & $\begin{array}{l}-0.42652^{* * *} \\
(-13.06)\end{array}$ & $\begin{array}{l}-1.8738^{* * *} \\
(-106.61)\end{array}$ & $\begin{array}{c}0.4087^{* * *} \\
(15.81)\end{array}$ & & & & & & \\
\hline $\begin{array}{r}\text { Grade II } \\
\text { Level B } \\
\text { hospitals }\end{array}$ & & & & $\begin{array}{l}-0.8093^{* * *} \\
(-14.04)\end{array}$ & $\begin{array}{l}1.2156^{* * *} \\
(68.99)\end{array}$ & $\begin{array}{c}-0.3141^{* * *} \\
(-10.86)\end{array}$ & & & \\
\hline $\begin{array}{l}\text { Grade I } \\
\text { hospitals }\end{array}$ & & & & & & & $\begin{array}{l}1.7973^{* * *} \\
(46.75)\end{array}$ & $\begin{array}{l}1.8962^{* * *} \\
(68.47)\end{array}$ & $\begin{array}{l}-0.2735^{* * *} \\
(-5.25)\end{array}$ \\
\hline $\begin{array}{l}\text { reimburse } \\
\text { ment ratio }\end{array}$ & $\begin{array}{l}-1.1098^{* * *} \\
(-12.15)\end{array}$ & $\begin{array}{l}-1.1074^{* * *} \\
(-16.46)\end{array}$ & $\begin{array}{l}6.3768^{* * *} \\
(87.27)\end{array}$ & $\begin{array}{l}-1.3412^{* * *} \\
(-14.84)\end{array}$ & $\begin{array}{c}-1.1129^{* * *} \\
(-16.74)\end{array}$ & $\begin{array}{l}6.4322^{* * *} \\
(87.76)\end{array}$ & $\begin{array}{l}-1.3619^{* * *} \\
(-14.80)\end{array}$ & $\begin{array}{c}-1.2963^{* * *} \\
(-19.74)\end{array}$ & $\begin{array}{l}6.5130^{* * *} \\
(89.33)\end{array}$ \\
\hline $\begin{array}{c}\text { medical } \\
\text { expenses }\end{array}$ & $\begin{array}{l}0.5612^{* * *} \\
(31.69)\end{array}$ & $\begin{array}{l}0.0298^{*} \\
(1.87)\end{array}$ & $\begin{array}{c}0.1621^{* * *} \\
(11.03)\end{array}$ & $\begin{array}{l}0.4904^{* * *} \\
(27.38)\end{array}$ & $\begin{array}{c}-0.2574^{* * *} \\
(-16.19)\end{array}$ & $\begin{array}{c}0.1901^{* * *} \\
(13.02)\end{array}$ & $\begin{array}{l}0.5974^{* * *} \\
(34.73)\end{array}$ & $\begin{array}{c}-0.2778^{* * *} \\
(-17.63)\end{array}$ & $\begin{array}{l}0.1939^{* * *} \\
(13.31)\end{array}$ \\
\hline Gender & $\begin{array}{l}-0.4553^{* * *} \\
(-17.97)\end{array}$ & $\begin{array}{l}-0.0729^{* * *} \\
(-4.40)\end{array}$ & $\begin{array}{l}0.0698^{* * *} \\
(5.21)\end{array}$ & $\begin{array}{l}-0.4534^{* * *} \\
(-17.89)\end{array}$ & $\begin{array}{c}-0.0456^{* * *} \\
(-2.78)\end{array}$ & $\begin{array}{l}0.0696^{* * *} \\
(5.20)\end{array}$ & $\begin{array}{l}-0.4804^{* * *} \\
(-18.86)\end{array}$ & $\begin{array}{c}-0.0445^{* * *} \\
(-2.71)\end{array}$ & $\begin{array}{l}0.0708^{* * *} \\
(5.29)\end{array}$ \\
\hline Age & $\begin{array}{l}0.0384^{* * *} \\
(45.97)\end{array}$ & $\begin{array}{l}0.0082^{* * *} \\
(21.32)\end{array}$ & $\begin{array}{c}-0.0017^{* * *} \\
(-4.44)\end{array}$ & $\begin{array}{l}0.0394^{* * *} \\
(47.70)\end{array}$ & $\begin{array}{c}0.0105^{* * *} \\
(27.86)\end{array}$ & $\begin{array}{c}-0.0022^{* * *} \\
(-5.64)\end{array}$ & $\begin{array}{l}0.0355^{* * *} \\
(42.88)\end{array}$ & $\begin{array}{l}0.0111^{* * *} \\
(30.19)\end{array}$ & $\begin{array}{l}-0.0018^{* * *} \\
(-4.52)\end{array}$ \\
\hline $\begin{array}{l}\text { Length of } \\
\text { day }\end{array}$ & $\begin{array}{l}0.0056^{* * *} \\
(9.12)\end{array}$ & $\begin{array}{l}-0.1241^{* * *} \\
(-40.88)\end{array}$ & $\begin{array}{c}-0.0036^{* * *} \\
(-3.64)\end{array}$ & $\begin{array}{l}0.0065^{* * *} \\
(9.34)\end{array}$ & $\begin{array}{c}-0.0942^{* * *} \\
(-31.99)\end{array}$ & $\begin{array}{c}-0.0054^{* * *} \\
(-5.33)\end{array}$ & $\begin{array}{l}0.0044^{* * *} \\
(9.59)\end{array}$ & $\begin{array}{c}-0.1022^{* * *} \\
(-36.50)\end{array}$ & $\begin{array}{l}-0.0047^{* * *} \\
(-4.67)\end{array}$ \\
\hline $\begin{array}{l}\text { Disease } \\
\text { type }\end{array}$ & $\begin{array}{l}-0.1270^{* * *} \\
(-5.48)\end{array}$ & $\begin{array}{l}0.0172 \\
(0.85)\end{array}$ & $\begin{array}{c}-0.2243^{* * *} \\
(-20.40)\end{array}$ & $\begin{array}{l}-0.1234^{* * *} \\
(-5.33)\end{array}$ & $\begin{array}{l}0.0209 \\
(1.05)\end{array}$ & $\begin{array}{c}-0.2264^{* * *} \\
(-20.58)\end{array}$ & $\begin{array}{l}-0.1394^{* * *} \\
(-5.94)\end{array}$ & $\begin{array}{l}0.0185 \\
(0.93)\end{array}$ & $\begin{array}{l}-0.2276^{* * *} \\
(-20.72)\end{array}$ \\
\hline
\end{tabular}




\begin{tabular}{|c|c|c|c|c|c|c|c|c|c|}
\hline $\begin{array}{l}\text { Constant } \\
\text { term }\end{array}$ & $\begin{array}{l}-11.1833^{* * *} \\
(-68.36)\end{array}$ & $\begin{array}{l}-1.4506^{* * *} \\
(-13.14)\end{array}$ & $\begin{array}{c}-9.0475^{* * *} \\
(-80.10) \\
\end{array}$ & $\begin{array}{c}-10.8116^{* * *} \\
(-64.67) \\
\end{array}$ & $\begin{array}{c}-1.0686^{* * *} \\
(-9.52)\end{array}$ & $\begin{array}{c}-8.8721^{* * *} \\
(-77.57) \\
\end{array}$ & $\begin{array}{c}-11.4566^{* * *} \\
(-70.96) \\
\end{array}$ & $\begin{array}{c}-0.6036^{* * *} \\
(-5.43)\end{array}$ & $\begin{array}{l}-8.9898^{* * *} \\
(-79.39) \\
\end{array}$ \\
\hline $\begin{array}{l}\text { Log } \\
\text { likelihood }\end{array}$ & \multicolumn{3}{|c|}{-182970.08} & \multicolumn{3}{|c|}{-186460.96} & \multicolumn{3}{|c|}{-186296.56} \\
\hline Prob $>\mathrm{chi}^{2}$ & \multicolumn{3}{|c|}{0.0000} & \multicolumn{3}{|c|}{0.0000} & \multicolumn{3}{|c|}{0.0000} \\
\hline Pseudo $\mathrm{R}^{2}$ & \multicolumn{3}{|c|}{0.1095} & \multicolumn{3}{|c|}{0.0925} & \multicolumn{3}{|c|}{0.0933} \\
\hline $\mathrm{N}$ & \multicolumn{3}{|c|}{519471} & \multicolumn{3}{|c|}{519471} & \multicolumn{3}{|c|}{519471} \\
\hline
\end{tabular}

Notes: ${ }^{* * *}$ significant at $1 \%,{ }^{* *}$ significant at $5 \%,{ }^{*}$ significant at $10 \%$, t-statistics in parentheses.

In this paper, data from UEBMI of Chengdu City were used to further examine the effect of hospital levels on the equity of Medical Outcomes after distinguishing $\mathrm{COH}$. The empirical results were presented in table 4. According to the empirical results, the effect of Grade II Level A hospitals on death and transfer was significantly negative, while the effect on no cure was significantly positive. The effect of Grade II Level B hospitals on death and no cure were significantly negative, and the effect of Grade II Level B hospitals on transfer was significantly positive. The effect of Grade II Level C hospitals on death and transfer was significantly positive, while the effect of no cure I was significantly negative. This indicates that hospital levels had an important impact on the equity of Medical Outcomes. From a horizontal perspective, hospitals of the same level had different effects on different the equity of Medical Outcomes. This could be related to the types and severity of the disease. From a longitudinal perspective, different levels of hospitals had different effects on the equity of Medical Outcomes. It was not the case that the higher the level of hospitals, the better the medical effect. This indicated that the medical outcome of large hospitals (high-level hospitals) was not necessarily better than that of small hospitals (low-level hospitals). The reason could be that high-level hospitals had obvious competitive advantages compared with low-level hospitals. For diseases that could not be treated by low-level hospitals, especially for cancer and tumours, high-level hospitals could provide advanced technology and more professional doctors, and the 
medical outcome was obviously better than that of low-level hospitals. Nevertheless, with the progress of medical technology, the homogeneity of competition between different levels was obvious. With regard to the homogeneity of disease treatment, lower-level hospitals had an advantage over higher-level hospitals, such as lower cost and better service, especially for chronic diseases and common diseases, and the medical outcome of lower-level hospitals was relatively good.

Table 5 NMNL Empirical Results (by disease types)

\begin{tabular}{|c|c|c|c|}
\hline \multirow{2}{*}{ Variables } & \multicolumn{3}{|c|}{ Treatment outcome } \\
\hline & Death & Transfer & Others \\
\hline Hospital levels & $\begin{array}{c}0.4480^{* * *} \\
(13.57)\end{array}$ & $\begin{array}{c}1.8224 * * * \\
(101.11)\end{array}$ & $\begin{array}{c}-0.3668 * * * \\
(-14.16)\end{array}$ \\
\hline $\begin{array}{c}\text { reimbursement } \\
\text { ratio } \\
\end{array}$ & $\begin{array}{c}-1.1874 * * * \\
(-12.90) \\
\end{array}$ & $\begin{array}{c}-1.2968^{* * *} \\
(-18.52) \\
\end{array}$ & $\begin{array}{c}6.3161 * * * \\
(86.27) \\
\end{array}$ \\
\hline $\begin{array}{l}\text { medical } \\
\text { expenses }\end{array}$ & $\begin{array}{c}0.5749^{* * *} \\
(28.24)\end{array}$ & $\begin{array}{c}0.0738 * * * \\
(4.45)\end{array}$ & $\begin{array}{c}0.1094 * * * \\
(7.35)\end{array}$ \\
\hline Gender & $\begin{array}{c}-0.45503 * * * \\
(-17.91) \\
\end{array}$ & $\begin{array}{c}-0.0758 * * * \\
(-4.41) \\
\end{array}$ & $\begin{array}{c}0.0714 * * * \\
(5.32) \\
\end{array}$ \\
\hline Age & $\begin{array}{c}0.0371 * * * \\
(42.08) \\
\end{array}$ & $\begin{array}{c}0.0111 * * * \\
(30.19)\end{array}$ & $\begin{array}{c}-0.0031 * * * \\
(-7.86) \\
\end{array}$ \\
\hline Length of day & $\begin{array}{l}-0.0001 \\
(-0.12)\end{array}$ & $\begin{array}{c}-0.1285^{* * *} \\
(-41.15)\end{array}$ & $\begin{array}{c}-0.0034 * * * \\
(-3.42)\end{array}$ \\
\hline \multicolumn{4}{|l|}{ Disease type } \\
\hline Critical disease & $\begin{array}{c}1.8656^{* * *} \\
(19.62)\end{array}$ & $\begin{array}{l}0.0730 \\
(1.17)\end{array}$ & $\begin{array}{c}0.8804 * * * \\
(27.42)\end{array}$ \\
\hline Others & $\begin{array}{c}0.9320 * * * \\
(10.19)\end{array}$ & $\begin{array}{l}0.0442 \\
(0.96)\end{array}$ & $\begin{array}{l}-0.0111 \\
(-0.40)\end{array}$ \\
\hline Constant term & $\begin{array}{c}-13.1579 * * * \\
(-62.91)\end{array}$ & $\begin{array}{c}-5.4037 * * * \\
(-42.35) \\
\end{array}$ & $\begin{array}{c}-8.1251^{* * * *} \\
(-65.58)\end{array}$ \\
\hline Log likelihood & & -178250.54 & \\
\hline Prob $>$ chi $^{2}$ & & 0.0000 & \\
\hline Pseudo $\mathrm{R}^{2}$ & & 0.1111 & \\
\hline
\end{tabular}




\begin{tabular}{|c|c|}
\hline $\mathrm{N}$ & \\
& 512658 \\
\hline
\end{tabular}

Notes: ${ }^{* *}$ significant at $1 \%,{ }^{* *}$ significant at $5 \%,{ }^{*}$ significant at $10 \%$, t-statistics in parentheses.

In this study, we used data from UEBMI of Chengdu City to assess the effect of hospital levels on medical outcome after distinguishing disease types. The empirical results were presented in Table 5. According to the empirical results, the effect of hospital level on medical outcome was significant, the effect of hospital level on death and transfer is significantly positive, and the effect on no cure is significantly negative. The type of disease influenced the medical outcome. Taking chronic disease as the reference group, the effect of critical disease on medical outcome was positive, indicating that the higher the severity of the disease, the higher the probability of death and transfer. Disease types influenced medical outcome. Distinct types of disease should be addressed in different levels of hospitals, which requires that family doctors made an accurate diagnosis when patients first saw a physician. This type of tiered delivery system could achieve the goal of slight illness in the community, serious diseases in the hospital, rehabilitation back to the community. The tiered delivery system met the medical needs of patients with different types of disease and improved the quality and levels of medical services.

\section{Robustness check}

To check the robustness of the model, this paper made use of the data from UEBMI of Chengdu city. After distinguishing hospital levels and disease types, we further tested the impact of hospital level on medical outcome. The empirical results were shown in Table 6.

According to the empirical results, the influence of hospital level on medical outcome was 
significant. The effect of Grade II Level A on death and transfer was significantly negative, and the effect on no cure was significantly positive. The type of disease affects the medical outcome. Taking chronic disease as the reference group, the effect of critical disease on death and no cure are significantly positive, which indicated that the more severe the disease was, the higher the probability of death and transfer. Grade II Level A hospitals played a limited role in curing critical diseases. Grade II Level B hospitals had significantly negative effects on death and no cure and significantly positive effects on transfer. This indicated that Grade II Level B hospitals did not have the ability to admit and treat patients with critical diseases, which had a negative effect on improving the medical outcome of these patients. The effect of Grade II Level C hospitals on death and transfer was significantly positive, while the effect on no cure was significantly negative. Grade II Level C hospitals had a more significant negative effect on improving the medical outcome of critical disease. Grade II Level C hospitals had higher transfer rates for different disease types. However, compared with critical diseases, Grade II Level A hospitals and Grade II Level B hospitals played a role in improving the medical outcome of chronic diseases. This showed that the hospital level had different degrees of effect on the medical outcome of different disease types. In terms of critical diseases, higher-level hospitals had a more significant effect on improving the equity of Medical Outcomes, while lower-level hospitals had a significantly negative effect on the equity of Medical Outcomes. However, for chronic diseases and common diseases, the effect of high-level hospitals on improving the equity of Medical Outcomes was not significant. Especially for chronic diseases, the effect of low-level hospitals on improving the equity of Medical Outcomes was better than that of high-level hospitals. In conclusion, hospitals of different levels should be reasonably selected for different types of diseases to achieve the optimal medical outcome. After distinguishing hospital level and 
disease type, the empirical consequences of the MMNL model in table 3, 4 and 5 showed that the regression results were relatively robust.

Table 6 NMNL Empirical Results (by hospital levels and disease types)

\begin{tabular}{|c|c|c|c|c|c|c|c|c|c|}
\hline \multirow{2}{*}{ Variables } & \multicolumn{9}{|c|}{ Treatment outcome } \\
\hline & Death & Transfer & Others & Death & Transfer & Others & Death & Transfer & Others \\
\hline \multicolumn{10}{|l|}{$\begin{array}{l}\text { Hospital } \\
\text { levels }\end{array}$} \\
\hline $\begin{array}{c}\text { Grade II } \\
\text { Level A } \\
\text { hospitals }\end{array}$ & $\begin{array}{c}-0.3950^{* * *} \\
(-12.06)\end{array}$ & $\begin{array}{l}-1.8733^{* * *} \\
(-106.58)\end{array}$ & $\begin{array}{c}0.4337^{\text {**** }} \\
(16.73)\end{array}$ & & & & & & \\
\hline $\begin{array}{c}\text { Grade II } \\
\text { Level B } \\
\text { hospitals }\end{array}$ & & & & $\begin{array}{c}-0.83304^{* * * *} \\
(-14.39)\end{array}$ & $\begin{array}{c}1.2154^{* * * *} \\
(68.98)\end{array}$ & $\begin{array}{c}-0.3258^{* * *} \\
(-11.25)\end{array}$ & & & \\
\hline $\begin{array}{l}\text { Grade I } \\
\text { hospitals }\end{array}$ & & & & & & & $\begin{array}{c}1.7362^{* * *} \\
(44.81)\end{array}$ & $\begin{array}{c}1.8946^{* * *} \\
(68.4)\end{array}$ & $\begin{array}{c}-0.3326^{\text {*** }} \\
(-6.36)\end{array}$ \\
\hline $\begin{array}{c}\text { reimbursem } \\
\text { ent ratio }\end{array}$ & $\begin{array}{l}-1.2352^{* * * *} \\
(-13.48)\end{array}$ & $\begin{array}{l}-1.1084^{* * * *} \\
(-16.47)\end{array}$ & $\begin{array}{c}6.2921^{* * *} \\
(86.06)\end{array}$ & $\begin{array}{c}-1.4661^{* * *} \\
(-16.17)\end{array}$ & $\begin{array}{l}-1.1138^{* * *} \\
(-16.75)\end{array}$ & $\begin{array}{c}6.3528^{* * *} \\
(86.6)\end{array}$ & $\begin{array}{l}-1.4778^{* * *} \\
(-16.00)\end{array}$ & $\begin{array}{c}-1.2959^{* * *} \\
(-19.73)\end{array}$ & $\begin{array}{l}6.4336^{* * * *} \\
(88.19)\end{array}$ \\
\hline $\begin{array}{l}\text { Medical } \\
\text { expenses }\end{array}$ & $\begin{array}{c}0.5233^{* * *} \\
(29.22)\end{array}$ & $\begin{array}{l}0.0294^{*} \\
(1.85)\end{array}$ & $\begin{array}{c}0.1197^{* * * *} \\
(8.09)\end{array}$ & $\begin{array}{l}0.4529^{* * * *} \\
(25.05)\end{array}$ & $\begin{array}{l}-0.2578^{* * *} \\
(-16.20)\end{array}$ & $\begin{array}{c}0.1512^{* * *} \\
(10.29)\end{array}$ & $\begin{array}{l}0.5635^{* * *} \\
(32.53)\end{array}$ & $\begin{array}{l}-0.2782^{* * * *} \\
(-17.64)\end{array}$ & $\begin{array}{c}0.1527^{* * * *} \\
(10.41)\end{array}$ \\
\hline Gender & $\begin{array}{c}-0.4496^{* * *} \\
(-17.72)\end{array}$ & $\begin{array}{c}-0.0728^{* * *} \\
(-4.39)\end{array}$ & $\begin{array}{c}0.07211^{* * * *} \\
(5.36)\end{array}$ & $\begin{array}{c}-0.4485^{* * * *} \\
(-17.67)\end{array}$ & $\begin{array}{c}-0.0455^{* * *} \\
(-2.78)\end{array}$ & $\begin{array}{c}0.0720^{* * *} \\
(5.36)\end{array}$ & $\begin{array}{c}-0.4732^{* * *} \\
(-18.54)\end{array}$ & $\begin{array}{c}-0.0444^{* * *} \\
(-2.71)\end{array}$ & $\begin{array}{c}0.0733^{* * * *} \\
(5.46)\end{array}$ \\
\hline Age & $\begin{array}{c}0.0368^{* * *} \\
(43.99)\end{array}$ & $\begin{array}{c}0.0082^{* * * *} \\
(21.25)\end{array}$ & $\begin{array}{c}-0.0031^{* * * *} \\
(-7.77) \\
\end{array}$ & $\begin{array}{c}0.0378^{* * *} \\
(45.67) \\
\end{array}$ & $\begin{array}{c}0.0104^{\text {*** }} \\
(27.77)\end{array}$ & $\begin{array}{c}-0.0036^{\text {*** }} \\
(-9.07)\end{array}$ & $\begin{array}{c}0.0341^{* * * *} \\
(41.1)\end{array}$ & $\begin{array}{c}0.0111^{* * *} \\
(30.08)\end{array}$ & $\begin{array}{r}-0.0036^{* * *} \\
(-9.06)\end{array}$ \\
\hline $\begin{array}{c}\text { Length of } \\
\text { day }\end{array}$ & $\begin{array}{c}0.0056^{* * *} \\
(8.9)\end{array}$ & $\begin{array}{l}-0.1241^{* * * *} \\
(-40.88)\end{array}$ & $\begin{array}{c}-0.0033^{* * *} \\
(-3.37)\end{array}$ & $\begin{array}{c}0.0066^{* * *} \\
(9.32)\end{array}$ & $\begin{array}{l}-0.0942^{* * *} \\
(-32.00)\end{array}$ & $\begin{array}{c}-0.0054^{* * *} \\
(-5.27)\end{array}$ & $\begin{array}{c}0.0044^{* * *} \\
(9.48)\end{array}$ & $\begin{array}{c}-0.1023^{* * *} \\
(-36.51)\end{array}$ & $\begin{array}{c}-0.0044^{* * *} \\
(-4.37)\end{array}$ \\
\hline $\begin{array}{l}\text { Disease } \\
\text { type }\end{array}$ & & & & & & & & & \\
\hline $\begin{array}{l}\text { Critical } \\
\text { diseas } \\
\text { e }\end{array}$ & $\begin{array}{c}1.8814^{* * *} \\
(19.79)\end{array}$ & $\begin{array}{l}0.0479 \\
(0.79)\end{array}$ & $\begin{array}{c}0.8845^{\text {**** }} \\
(27.25)\end{array}$ & $\begin{array}{c}1.9198^{* * *} \\
(20.20)\end{array}$ & $\begin{array}{l}0.0588 \\
(0.98)\end{array}$ & $\begin{array}{c}0.8728^{* * * *} \\
(27.2)\end{array}$ & $\begin{array}{c}1.7944^{* * *} \\
(18.83)\end{array}$ & $\begin{array}{l}0.0506 \\
(0.84)\end{array}$ & $\begin{array}{c}0.8730^{* * * *} \\
(27.2)\end{array}$ \\
\hline $\begin{array}{l}\text { Disease } \\
\text { type }\end{array}$ & $\begin{array}{c}0.9374^{* * *} \\
(10.25)\end{array}$ & $\begin{array}{l}0.0443 \\
(1.01)\end{array}$ & $\begin{array}{l}-0.0096 \\
(-0.34)\end{array}$ & $\begin{array}{c}0.9145^{\text {*** }} \\
(10.46)\end{array}$ & $\begin{array}{l}0.0549 \\
(1.27)\end{array}$ & $\begin{array}{c}-0.01658 \\
(-0.59)\end{array}$ & $\begin{array}{c}0.8795^{\text {**** }} \\
(9.61)\end{array}$ & $\begin{array}{l}0.0483 \\
(1.11)\end{array}$ & $\begin{array}{l}-0.0186 \\
(-0.66)\end{array}$ \\
\hline $\begin{array}{l}\text { Constant } \\
\text { term }\end{array}$ & $\begin{array}{c}-11.8746^{* * *} \\
(-65.90)\end{array}$ & $\begin{array}{c}-1.4554^{* * *} \\
(-13.12)\end{array}$ & $\begin{array}{c}-9.0015^{* * *} \\
(- \\
79.06)\end{array}$ & $\begin{array}{c}-11.4890^{* * * *} \\
(-62.69)\end{array}$ & $\begin{array}{c}-1.0766^{* * *} \\
(-9.54)\end{array}$ & $\begin{array}{c}-8.8291^{* * *} \\
(-76.51)\end{array}$ & $\begin{array}{c}-12.1370^{* * *} \\
(-68.30)\end{array}$ & $\begin{array}{c}-0.6098^{* * *} \\
(-5.46)\end{array}$ & $\begin{array}{l}-8.9325^{* * *} \\
(-78.26)\end{array}$ \\
\hline $\begin{array}{l}\text { Log } \\
\text { likelihood }\end{array}$ & & -181840.89 & & & -185328.86 & & & -185213.83 & \\
\hline Prob $>\mathrm{chi}^{2}$ & & 0.0000 & & & 0.0000 & & & 0.0000 & \\
\hline
\end{tabular}




\begin{tabular}{|c|c|c|c|}
\cline { 2 - 4 } Pseudo $\mathrm{R}^{2}$ & 0.1149 & 0.0980 & 0.0985 \\
\hline $\mathrm{N}$ & 519471 & 519471 & 519471 \\
\hline
\end{tabular}

Notes: ${ }^{* * *}$ significant at $1 \%,{ }^{* *}$ significant at $5 \%,{ }^{*}$ significant at $10 \%$, t-statistics in parentheses.

\section{Discussion}

The traditional idea that the medical care provided by a large hospital is better is still deeply rooted in people's minds. The characteristics of the medical inverted pyramid structure- higherlevel medical institutions are overwhelmed, while lower-level medical institutions are desertedhas existed for a long time. Because of the unreasonable allocation of resources, it is challenging to meet the health care needs of citizens and to establish a tiered delivery system.

Although the relationship between $\mathrm{COH}$ and the equity of Medical Outcomes of patients has attracted great attention from scholars all over the world, there are only a few studies which provide for different outcomes of patients perspective, especially using the data from UEBMI of Chengdu city by NMNL to estimate the effect of the $\mathrm{COH}$ on the equity of Medical Outcomes. This paper attempts to introduce the research field of the influence of $\mathrm{COH}$ on the equity of Medical Outcomes of patients, and revealed some important findings.

Firstly, $\mathrm{COH}$ had a significant effect on the equity of Medical Outcomes, but the degree of influence and direction of the hospital level on different outcomes were not consistent. The effect of hospital level on death and transfer was significantly positive, and the effect on no cure was significantly negative, which could be related to the type and severity of disease. Some scholars had estimated the effect of hospital size on the equity of Medical Outcomes with mixed results. Sjetne et al. [16] used the Patients' Experience Questionnaire (PEQ) to study the effect of hospital size and type on hospital care in 50 Norwegian hospitals. They found that hospital size and type influence 
patients' experience and the equity of Medical Outcomes. Reinikainen et al. [17] achieved the same results. There was a large body of empirical literatures on the relationship between hospital types and the equity of Medical Outcomes. There were two dominant types. On the one hand, hospitals could be divided into teaching hospitals and non-teaching hospitals. Most researchers had found that teaching status affects the equity of Medical Outcomes and that teaching hospitals offer better the equity of Medical Outcomes [18-23]. In contrast, Fleming et al. [24] found lower mortality rates in non-teaching hospitals than in teaching hospitals. Some researchers had also concluded that there were no differences in the equity of Medical Outcomes between teaching and non-teaching hospitals [25-28]. On the other hand, hospitals could be classified into government-owned hospitals, forprofit hospitals and not-for-profit hospitals according to their ownership. A systematic review of the literature reports mixed results: whether hospital ownership impacts the equity of Medical Outcomes, as measured by mortality rates and other adverse events, depends on the region, the data source and the period of analysis [29]. Many studies had found that hospital ownership matters for the equity of Medical Outcomes. Some studies had found that private hospitals had better therapeutic outcomes [30-33], some had found that not-for-profit hospitals had better therapeutic outcomes [34-36], while others have found that for-profit hospitals had better the equity of Medical Outcomes [37]. However, some studies had found no difference in therapeutic outcomes by ownership type in America [38-41].

Secondly, the reimbursement rate, medical expenditure, gender, age, disease type and other factors were associated with the equity of Medical Outcomes. Length of stay had an effect on the medical outcome, but not all of these were uniformly significant, indicating that it was not the case that the longer the stay was, the better the outcome would be. Studies on the relationship between 
hospital service capacity and the equity of Medical Outcomes had been conducted for more than 30 years, but there was still no definite conclusion. Many scholars considered some acute diseases or operations as examples to study the correlation between them. The research results were mainly divided into two categories: the first suggested that the hospital service volume was positively related to the curative outcome [43], while the second suggested that the two are unrelated. [42] [44]. There were also studies on the correlation between hospital accreditation and medical outcome. Most of the research results showed that hospital accreditation could improve healing outcomes [4546]. Numerous scholars had examined the relationship between hospital competition and the equity of Medical Outcomes. The evidence was mixed. Kessler and McClellan [47] and Hugh et al. [48] found a positive effect of competition on the equity of Medical Outcomes. However, Shortell and Hughes [49] and Mukamel et al. [50] found no effect. Propper et al. [51] exploited a policy change by the UK government for the 1990s and found that competition was associated with worse the equity of Medical Outcomes. Gowrisankaran and Town [52] reached the same conclusion as Propper et al. Additionally, many studies had examined medical insurance. Most of the results indicated that medical insurance impacted the equity of Medical Outcomes [53-55]

Thirdly, after distinguishing the classification of hospitals, there were significant differences in the influence of different levels of hospitals on the medical effect. Horizontally speaking, hospitals of the same grade had different influences on different the equity of Medical Outcomes. There was competition between hospitals of the same grade. This result was similar to most previous studies in which hospital competition influences the equity of Medical Outcomes [47][48]. From a longitudinal perspective, different levels of hospitals had different impacts on the equity of Medical Outcomes. It was not the case that the higher the level of hospital, the better the medical effect. This 
indicated that the medical outcome of large hospitals (high-level hospitals) was not necessarily better than that of small hospitals (low-level hospitals).

Finally, after distinguishing hospital levels and disease types, the effect of hospitals of different levels on the medical outcome of different disease types was significantly different. In terms of critical diseases, higher-level hospitals had a more significant effect on improving the equity of Medical Outcomes, while lower-level hospitals had a significantly negative effect on the equity of Medical Outcomes. However, for chronic diseases and common diseases, the effect of high-level hospitals on improving the equity of Medical Outcomes was not significant. Especially for chronic diseases, the effect of low-level hospitals on improving the equity of Medical Outcomes was better than that of high-level hospitals. In conclusion, hospitals of different levels should be reasonably selected for different types of diseases to achieve the optimal medical outcome.

In conclusion, there was no relevant research on the effect of hospital classification on the equity of Medical Outcomes at home or abroad. Chinese scholars focused more on healthcare service utilization, healthcare demand and health care-seeking behaviour, while scholars from other countries focused on hospital scale, hospital type, hospital volume, hospital accreditation and medical insurance. Although these studies were relevant to therapeutic outcome, there was no pioneering research on the effect of hospital classification on the equity of Medical Outcomes at home and abroad. The possible reasons were as followed: (a) Medical outcome was a difficult index to measure and lacks a clear measurement; (b) Foreign healthcare systems were very different from China's system because foreign systems did not have a strict $\mathrm{COH}$, and hospitals differ in terms of scale and ownership type. Furthermore, in countries such as the UK and the US, hospitals had a high degree of homogenization because of the advanced healthcare system. At the same time, the 
family doctor system prevented patients from freely choosing doctors and hospitals, so the effect of hospital classification was relatively weak. However, hospitals were divided into different levels in a more detailed way in China, and there was a large gap in the quality and capability of healthcare services between different levels, which had a significant impact on the equity of Medical Outcomes. (c) Many factors affected the therapeutic outcome and could not all be included, and relevant data was difficult to obtain. Therefore, this paper presented an exploratory study of the effect of $\mathrm{COH}$ on the equity of Medical Outcomes.

\section{Conclusion}

In summary, our study on the effect of hospital classification on the equity of Medical Outcomes proposed the following policy suggestions to promote the construction of a tiered delivery system, as shown in figure 4: (a) Strengthen the publicity of a tiered delivery system and correct the traditional idea. At the same time, the government should improve the service quality and service capacity of grassroots medical institutions to ensure the equity of Medical Outcomes. (b) Let medical insurance play a role in a tiered delivery system. The effect of the reimbursement ratio on medical outcome is meaningful. The government should adjust the reimbursement ratio to the hospital level and gradually establish the reimbursement ratio in combination with hospital levels and disease types. For example, there is a higher reimbursement ratio for critical disease in high-level hospitals and a higher reimbursement ratio for chronic disease, common disease and frequently occurring disease in low-level hospitals. (c) Optimize the allocation structure of medical resources and promote the sinking of high-quality medical resources to the grassroots level. The government should provide more financial subsidies for grassroots-level medical institutions, 
encourage outstanding doctors to conduct multisite practices and improve the ability and level of grassroots-level medical institutions. (d) Let the market play the leading role. The government should encourage social capital to tilt to the grassroots and provide grassroots medical institutions with high-quality medical resources to meet the people's growing need for medical services.

In general, the impact of $\mathrm{COH}$ on the equity of Medical Outcomes of patients was heterogeneous. Hospitals of different level have different influences on the equity of Medical Outcomes. In the process of improving the equity of Medical Outcomes, the government should not only start from the supply side of healthcare services, such as reforming medical insurance payment, new technologies and equipment for $\mathrm{COH}$.

\section{Abbreviations}

COH: Classification of Hospitals; UEBMI: Urban Employee Basic Medical Insurance;

MNL: Multinomial Logit Model; IIA: Independence of Irrelevant Alternatives;

NMNL: Nested Multinomial Logit Model

\section{Acknowledgements}

We thank the Healthcare Security Administration of Chengdu City for cooperation and organizing data collection. We would also like to thank all study participants for their time to be interviewed.

Dr. Li would also like to thank professor Winnie Yip of school of public health in Harvard University. 


\section{Authors' contributions}

LL and SZ carried out the study, analysed the data and drafted the manuscript. TD and LL was responsible for writing the literary and revising the language. LL provided the guidance for revising the manuscript. All authors read and approved the final manuscript.

\section{Funding}

Not applicable.

\section{Availability of data and materials}

Data and materials are from Healthcare Security Administration of Chengdu City. All data generated or analysed during this study are included in this published article and its supplementary information files. It is not an open-access database.

\section{Ethics approval and consent to participate}

The data the study has been used is non-identifiable and and no patient is identified. The study was exempt from human subjects' approval by Healthcare Security Administration of Chengdu City.

\section{Consent for publication}

Not applicable.

\section{Competing interests}

The authors declare that they have no competing interests. 


\section{Author details}

a School of Labor and Human Resources, Renmin University of China, Beijing, China,100872,

${ }^{\mathrm{b}}$ Chinese Academy of Labor and Social Security, Beijing, China,100029;

${ }^{\mathrm{C}}$ Business School, Sichuan University, Chengdu, China,610065

\section{References}

1.Li HM,Xu HY.Whether Health Insurance Policy Can Promote the Realization of the Hierarchical Medical System: An Empirical Analysis Based on Medical Demand Behavior. Comparative Economic \& Social Systems, 2018(1):28-35.

2.Liu C,Zhou XH. Medical Information Spillovers and Health Care Choice of Chinese Residents in the Internet Era _ An Empirical Research Based on CHNS. Journal of Public Management, 2017(4):78-90.

3.Li YC.Formation mechanism of hierarchical diagnosis and treatment from the perspective of institutional structure. Modern Economic Research,2015(7):53-57.

4.Li XJ, Wang ZH,Lin ZP. The influence of the new rural cooperative medical service on the medical treatment behavior and health of farmers -- based on the analysis of different income levels. World Economic Paper, 2012(3):58-75.

5.Liu B,Hu SL. A study on income - related health inequalities: Evidence from Shanghai. Health Economic Research,2003(1):14-16.

6.Qian D,Pong RW, Yin A, et al. Determinants of health care demand in poor, rural China: the case of Gansu Province. Health Policy and Planning,2009,24(5):324-334. 
7.Han HW.A Review of Individual's Health Care Demand and Behavior Research. Economic Review,2010(7):146-153.

8.Ma XT.Impact of Hospital and Surgeon Volume on Outcomes of Colorectal Cancer Surgery. Medicine and Philosophy,2013,34(12):86-88.

9.Donabedian A. The quality of care: how can it be assessed? Jama, 1988, 260(12): 1743-1748.

10.Lohr K N. Outcome measurement: concepts and questions. Inquiry, 1988: 37-50.

11.Marra C, Johnston K, Santschi V, et al. Cost-effectiveness of pharmacist care for managing hypertension in Canada. Canadian Pharmacists Journal/Revue des Pharmaciens du Canada, 2017,150(3): 184-197.

12. Nagelkerke S C J, Mager D J, Benninga M A, et al. Reporting on outcome measures in pediatric chronic intestinal failure: a systematic review. Clinical Nutrition, 2019.

13. Korajkic A, Poole S G, MacFarlane L M, et al. Impact of a pharmacist intervention on ambulatory patients with heart failure: a randomised controlled study. Journal of Pharmacy Practice and Research, 2011,41(2): 126-131.

14. Mohammed A.Mohammed, Rebekah J.Moles, Jeff Harrison, Timothy F.Chen. Health Outcomes and Quality of Life. Encyclopedia of Pharmacy Practice and Clinical Pharmacy,2019: 59-72.

15. Craxford S, Deacon C, Mynt Y, et al. Assessing outcome measures used after rib fracture: a COSMIN systematic review. Injury, 2019.

16. Sjetne IS, Veenstra M, Stavem K. The effect of hospital size and teaching status on patient experiences with hospital care: a multilevel analysis. Medical care,2007,45(3): 252-258.

17. Reinikainen M, Karlsson S, Varpula T, et al. Are small hospitals with small intensive care units able to treat patients with severe sepsis?. Intensive care medicine, 2010,36(4): 673-679. 
18. Ayanian J Z, Weissman J S, Chasan-Taber S, et al. Quality of care for two common illnesses in teaching and nonteaching hospitals: teaching status appears to make a difference, when physicians and nurses assess hospitals' quality of care in four states. Health Affairs, 1998,17(6): 194-205.

19.Keeler E B, Rubenstein L V, Kahn K L, et al. Hospital characteristics and quality of care. Jama, 1992,268(13): 1709-1714.

20.Zimmerman J E, Shortell S M, Knaus W A, et al. Value and cost of teaching hospitals: a prospective, multicenter, inception cohort study. Critical care medicine, 1993,21(10): 1432-1442.

21. Kuhn E M, Hartz A J, Krakauer H, et al. The relationship of hospital ownership and teaching status to 30-and 180-day adjusted mortality rates. Medical care, 1994: 1098-1108.

22.Schultz M A, van Servellen G, Litwin M S, et al. Can hospital structural and financial characteristics explain variations in mortality caused by acute myocardial infarction?. Applied Nursing Research, 1999,12(4): 210-214.

23.Kuhn E M, Hartz A J, Gottlieb M S, et al. The relationship of hospital characteristics and the results of peer review in six large states. Medical Care, 1991: 1028-1038.

24.Fleming S T, McMahon J L F, Desharnais S I, et al. The measurement of mortality. A risk-adjusted variable time window approach. Medical care, 1991,29(9): 815-828.

25.Horbar J D, Badger G J, Lewit E M, et al. Hospital and patient characteristics associated with variation in 28-day mortality rates for very low birth weight infants. Pediatrics, 1997,99(2): 149156.

26. Whittle J, Lin C J, Lave J R, et al. Relationship of provider characteristics to outcomes, process, and costs of care for community-acquired pneumonia. Medical care, 1998: 977-987.

27.Cunningham W E, Tisnado D M, Lui H H, et al. The effect of hospital experience on mortality 
among patients hospitalized with acquired immunodeficiency syndrome in California. The American journal of medicine, 1999,107(2): 137-143.

28. Pearce W H, Parker M A, Feinglass J, et al. The importance of surgeon volume and training in outcomes for vascular surgical procedures. Journal of vascular surgery, 1999,29(5): 768-778.

29. Eggleston K, Shen Y C, Lau J, et al. Hospital ownership and quality of care: what explains the different results in the literature?. Health economics, 2008,17(12): 1345-1362.

30. Jensen P H, Webster E, Witt J. Hospital type and patient outcomes: an empirical examination using AMI readmission and mortality records. Health economics, 2009,18(12): 1440-1460.

31. Browne J, Jamieson L, Lewsey J, et al. Case-mix \& patients' reports of outcome in Independent Sector Treatment Centres: Comparison with NHS providers. BMC Health Services Research, 2008,8(1): 78 .

32. Moscelli G, Gravelle H, Siciliani L, et al. The effect of hospital ownership on quality of care: evidence from England. Journal of Economic Behavior \& Organization, 2018,153: 322-344.

33. Bjorvatn A. Private or public hospital ownership: Does it really matter? Social Science \& Medicine, 2018,196: 166-174.

34.Hartz A J, Krakauer H, Kuhn E M, et al. Hospital characteristics and mortality rates. New England journal of medicine, 1989,321(25): 1720-1725.

35. Briasoulis A, Inampudi C, Akintoye E, et al. Effect of Hospital Ownership on Outcomes After Left Ventricular Assist Device Implantation in the United States. The Annals of thoracic surgery, 2019,107(2): 527-532.

36. Shen Y C. The effect of hospital ownership choice on patient outcomes after treatment for acute myocardial infarction. Journal of Health Economics, 2002,21(5): 901-922. 
37. Milcent C. Hospital ownership, reimbursement systems and mortality rates. Health Economics, 2005,14(11): 1151-1168.

38. Duggan M G. Hospital ownership and public medical spending. The Quarterly Journal of Economics, 2000,115(4): 1343-1373.

39. Shah B R, Glickman S W, Liang L, et al. The impact of for-profit hospital status on the care and outcomes of patients with non-ST-segment elevation myocardial infarction: results from the CRUSADE Initiative. Journal of the American College of Cardiology, 2007,50(15): 1462-1468.

40. Sloan FA, Picone GA, Taylor Jr DH, et al. Hospital ownership and cost and quality of care: is there a dime's worth of difference?. Journal of health economics,2001,20(1):1-21.

41. Sloan F A, Trogdon J G, Curtis L H, et al. Does the ownership of the admitting hospital make a difference?: Outcomes and process of care of medicare beneficiaries admitted with acute myocardial infarction. Medical care, 2003,41(10): 1193-1205.

42.Lin XJ,Tao HB. Development of the relationship between hospital service capacity and quality of care. Chin J Hosp Admin,2016,32(2):108-110.

43.Enomoto LM, Gusani NJ, Dillon PW, et al. Impact of surgeon and hospital volume on mortality, length of stay, and cost of pancreaticoduodenectomy. Journal of Gastrointestinal Surgery,2014,18(4):690-700.

44.LaPar DJ,Kron IL, Jones DR, et al. Hospital procedure volume should not be used as a measure of surgical quality. Annals of surgery,2012,256(4): 606-615.

45.Alkhenizan A,Shaw C. Impact of accreditation on the quality of healthcare services: a systematic review of the literature. Annals of Saudi medicine,2011,31(4):407-416.

46.Kutney-Lee A,Stimpfel AW,Sloane DM,et al.Changes in patient and nurse outcomes associated 
with magnet hospital recognition. Medical care,2015,53(6):550.

47.Kessler D P, McClellan M B. Is hospital competition socially wasteful?. The Quarterly Journal of Economics, 2000,115(2): 577-615.

48.Gravelle H, Santos R, Siciliani L. Does a hospital's quality depend on the quality of other hospitals? A spatial econometrics approach. Regional science and urban economics, 2014,49: 203216.

49.Shortell S M, Hughes E F X. The effects of regulation, competition, and ownership on mortality rates among hospital inpatients. New England Journal of Medicine, 1988,318(17): 1100-1107.

50.Mukamel D B, Zwanziger J, Tomaszewski K J. HMO penetration, competition, and risk-adjusted hospital mortality[J]. Health services research, 2001,36(6 Pt 1): 1019.

51.Propper C, Burgess S, Gossage D. Competition and quality: evidence from the NHS internal market 1991-9. The Economic Journal, 2007;118(525): 138-170.

52. Gowrisankaran G, Town R J. Competition, payers, and hospital quality. Health Services Research, 2003,38(6p1): 1403-1422.

53. Kim T H, Park E C, Jang S I, et al. Effects of diagnosis-related group payment system on appendectomy outcomes. Journal of Surgical Research, 2016;206(2): 347-354.

54. Gillam S J, Siriwardena A N, Steel N. Pay-for-performance in the United Kingdom: impact of the quality and outcomes framework—a systematic review. The Annals of Family Medicine, 2012; 10(5): 461-468.

55. Kapoor J R, Kapoor R, Hellkamp A S, et al. Payment source, quality of care, and outcomes in patients hospitalized with heart failure. Journal of the American College of Cardiology, 2011;58(14): $1465-1471$. 


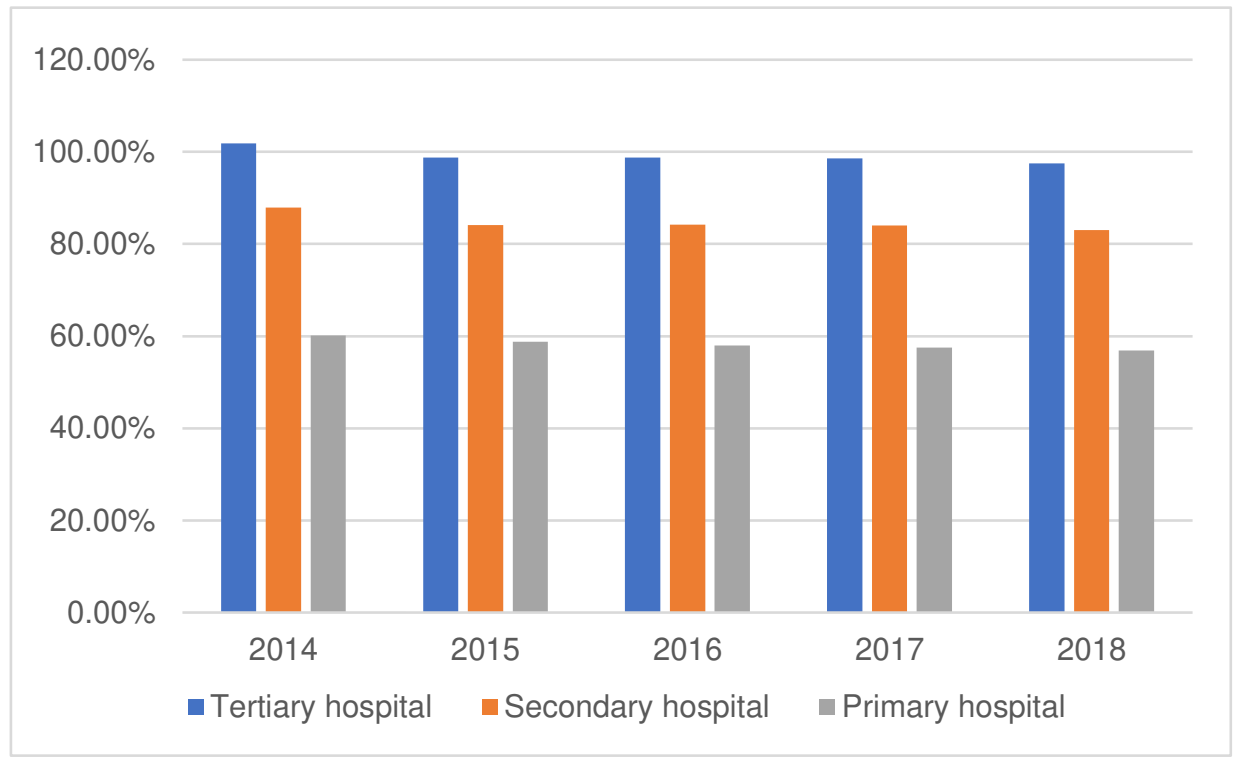

Figure 1 Utilization Rate of Bed in China

Data Source: China Health Statistical Yearbook:2014-2018.

Notes: Public hospitals refer to state-owned and collective-operated hospitals (including government-run hospitals). Private hospitals refer to hospitals other than public hospitals, including joint ventures, joint-stock cooperation, private hospitals, investment from Taiwan, Hong Kong and Macao, and foreign investment. Primary health care institutions include community health centers (stations), street health centers, township health centers (THCs), village clinics, outpatient departments, and clinics (infirmary). 


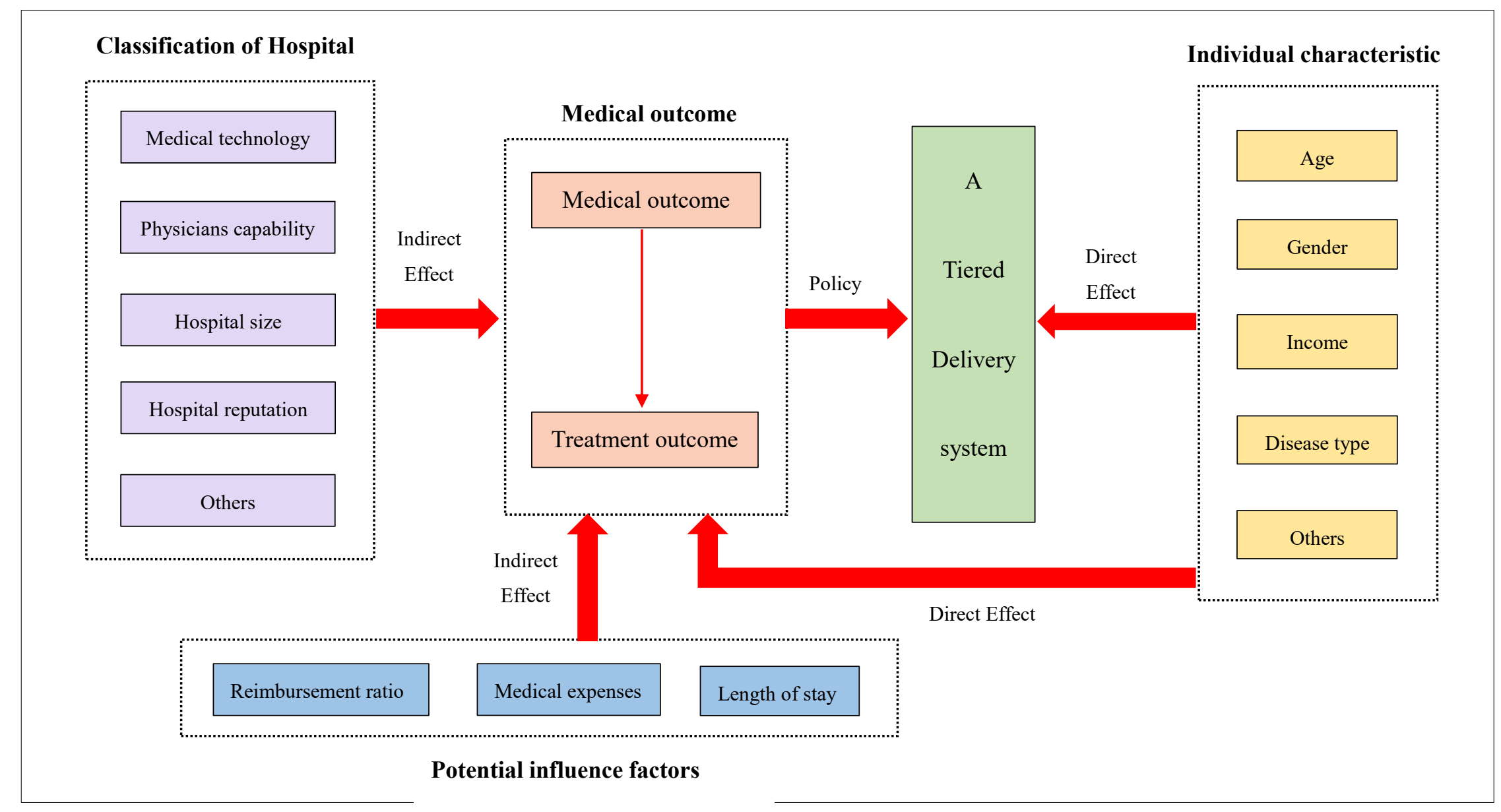

Figure 2 The mechanism of effect of Classification of Hospital on The equity of Medical Outcomes 


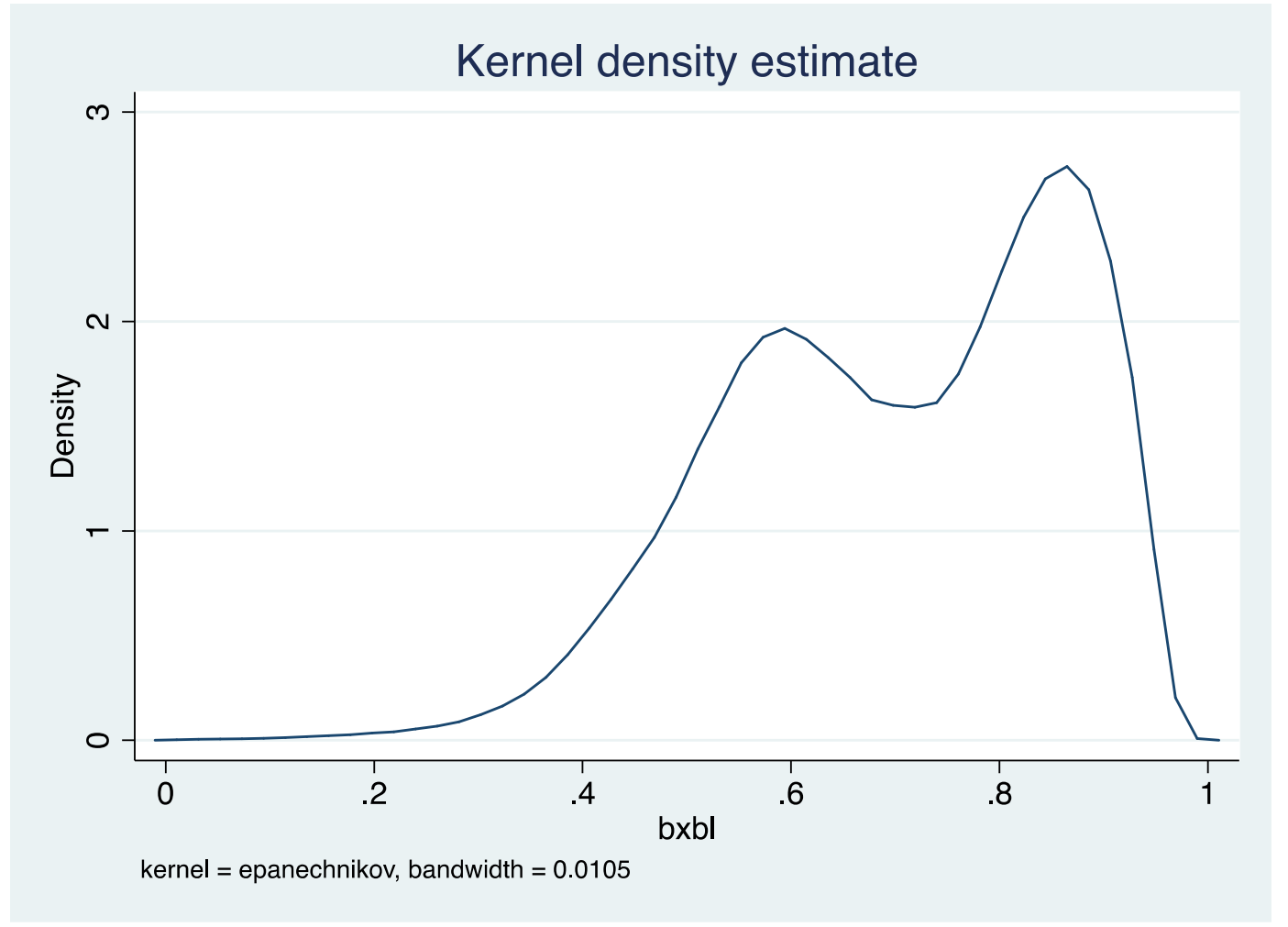

Figure 3 Density chart of reimbursement rates of medical insurance for different hospitals grades 


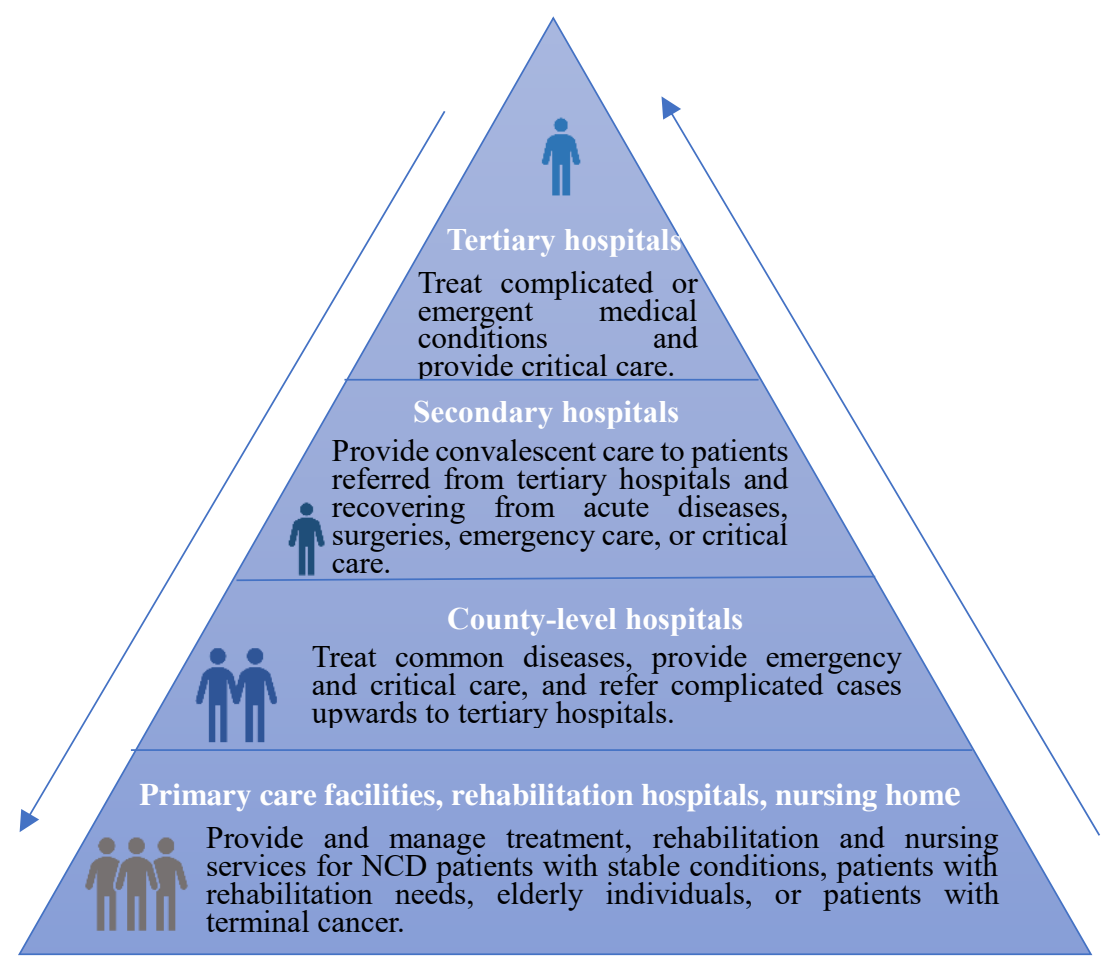

Figure 4 A tiered delivery system

Notes: According to Guidance of the General Office of the State Council on promoting a tiered delivery system. http://www.gov.cn/zhengce/content/2015-09/11/content_10158.html, Accessed date:26 September 2019. 